\title{
Carbohydrate-Deficient Transferrin Measurement
}

National Cancer Institute

\section{Source}

National Cancer Institute. Carbohydrate-Deficient Transferrin Measurement. NCI

Thesaurus. Code C101016.

The determination of the amount of transferrin with a reduced number of carbohydrate moieties present in a biological sample. 